\title{
A Simplified Model of a Surge Arrester and Its Application in Residual Voltage Tests
}

\author{
Peerawut Yutthagowith ${ }^{1, *}$, Sutee Leejongpermpoon ${ }^{1}$ and Nawakun Triruttanapiruk ${ }^{2}$ \\ 1 School of Engineering, King Mongkut's Institute of Technology Ladkrabang, Bangkok 10520, Thailand; \\ sutee509@hotmail.com \\ 2 Department of Electrical Engineering, Chubu University, 1200 Matsumoto-cho, Kasugai 487-8501, Japan; \\ nawakunt@gmail.com \\ * Correspondence: peerawut.yu@kmitl.ac.th; Tel.: +66-81-926-0141
}

Citation: Yutthagowith, P.;

Leejongpermpoon, S.;

Triruttanapiruk, N. A Simplified

Model of a Surge Arrester and Its

Application in Residual Voltage Tests.

Energies 2021, 14, 3132.

https://doi.org/10.3390/en14113132

Academic Editor: Christos

A. Christodoulou

Received: 10 March 2021

Accepted: 11 May 2021

Published: 27 May 2021

Publisher's Note: MDPI stays neutral with regard to jurisdictional claims in published maps and institutional affiliations.

Copyright: (c) 2021 by the authors. Licensee MDPI, Basel, Switzerland. This article is an open access article distributed under the terms and conditions of the Creative Commons Attribution (CC BY) license (https:// creativecommons.org/licenses/by/ $4.0 /)$.
Abstract: A simplified and accurate model of a surge arrester used in the residual voltage test is proposed in this paper. With the help of a genetic algorithm, the measured impulse current and residual voltage waveforms are utilized to determine circuit parameters of the proposed model and the generation circuit precisely. The technique starts from the circuit parameter determination using the preliminary experimental data with a lower current peak than that specified by the standard. From the determined model and with the help of the genetic algorithm, the circuit parameters and the charging voltage to obtain the specified current peak and the residual voltage can be estimated accurately. The validity of the proposed technique has been verified by experiments for the estimation of the appropriate current circuit parameters, the charging voltage, and the residual voltage. In addition, the application of the proposed model in the residual voltage tests is presented. From comparison of simulated and experimental results with the determined parameters, the impulse current and residual voltage waveforms are determined precisely. It is confirmed that the proposed model and technique are attractive in the appropriate circuit parameter determination and the residual voltage estimation in the residual voltage tests of surge arresters. The proposed method also provides a good advantage for reduction of the number of trial and error experiments for obtaining the current waveform according to the standard requirement. Moreover, the unintentional damages of the arrester during the process of the waveform adjustment will be reduced significantly.

Keywords: circuit parameter determination; impulse currents; surge arresters; residual voltage test; simplified arrester model

\section{Introduction}

A surge arrester is a device widely used to protect electrical equipment from overvoltages due to lightning and switching operation in electrical power and telecommunication systems [1]. The arrester exhibiting dynamic and nonlinear characteristics diverts current to the ground to clamp the over-voltage to be lower than the insulation level of the protected high voltage equipment. To confirm the performance in over-voltage mitigation, the international standards [2-5] advise performing residual voltage tests on the arrester.

According to the standard [3] and in the residual voltage tests, four kinds of impulse current waveforms, i.e., steep impulse current $(1 / 20 \mu \mathrm{s})$, high impulse current $(4 / 10 \mu \mathrm{s})$, lightning impulse current $(8 / 20 \mu \mathrm{s})$, and switching impulse current $(30 / 80 \mu \mathrm{s})$, in different current peaks are injected to the arrester during tests. The residual voltages across the arrester associated with the different impulse current waveforms and peaks are examined. The impulse currents can be generated by a simple resistance, inductance, and capacitance circuit as illustrated in Figure 1. The current generation circuit is composed of the DC voltage source $\left(V_{s}\right)$, the charging current limiting resistor $\left(R_{L}\right)$, the charging capacitor $(C)$, the spark gap $(G)$, the series inductor $\left(L_{e}\right)$, the series resistor $\left(R_{e}\right)$, the shunt current measuring resistor $\left(R_{S H}\right)$, and the surge arrester $(S A)$. 


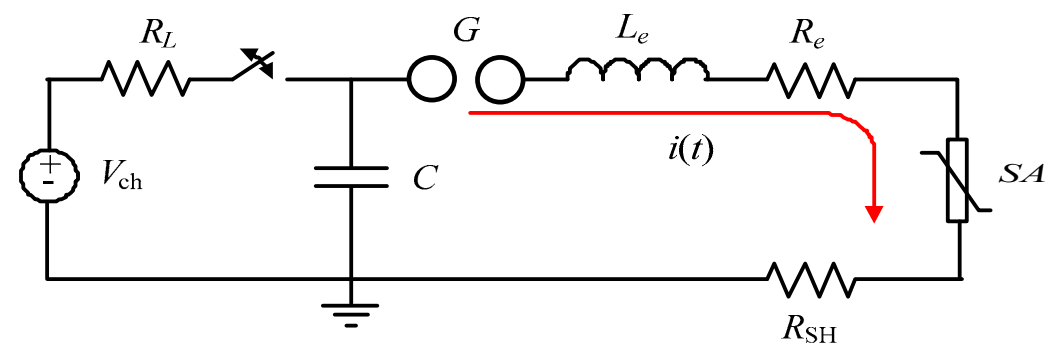

Figure 1. The impulse current generation circuit.

The most essential problem in residual voltage tests is that it is quite laborious for test engineers to generate an accurate waveform and a current peak according to the standard requirement, because the uncontrolled parasitic impedance in the current generation circuit and the nonlinear characteristic of the arrester affect the current waveform significantly. Therefore, an accurate arrester model is necessary to use in controlling the current waveform. There are a lot of researchers developing the accurate model used for designing insulation coordination and for obtaining successful high-voltage testing [6-14]. Furthermore, the effect of thermal stress under the arrester operation and experimental tests can be included in the model successfully [15]. However, the generation circuit and parasitic impedance are neglected in the process of model construction. It leads to the models not being appropriate in the residual voltage test in real practice. Therefore, trial and error approaches for selecting the circuit parameters and the charging voltage are still necessary to employ in the real experiment. Several experiments for waveform adjustment are carried out to obtain the required waveform and it sometimes unintentionally causes damage on the arrester during the test. It will be advantageous for test engineers if an effective technique for selecting the circuit parameters and the charging voltage is developed.

This paper aims to propose a simplified and accurate model of a surge arrester and an effective technique for selecting the circuit parameters and the charging voltage to obtain the specified impulse current waveform in residual voltage tests. Moreover, the residual voltage associated the impulse current waveform is estimated precisely. With the help of a genetic algorithm, the unknown parasitic impedance was determined, and the other appropriate circuit parameters and the charging voltage can be selected. The validity of the proposed technique was verified by the experiments for determination of the appropriate current circuit parameters, the charging voltage, and the residual voltage associated with the specified current waveform. From comparison of the experimental and simulated results, it was confirmed that the method is fairly highly accurate and very effective in the residual voltage tests of surge arresters. From this achievement, the proposed method is also very useful for the significant reduction of unintentional damages to the arrester during the process of waveform adjustment.

\section{Conventional Surge Arrester Model}

There are many proposed models of surge arresters but most of them are not applicable in residual voltage tests since the parasitic impedance and generation circuit are not taken into account in the process of model construction. For the sake of clarity, an experiment of the residual voltage test on a surge arrester with the rated voltage of $9 \mathrm{kV}$ and the nominal discharge current of $10 \mathrm{kA}$ was considered as a test case. As shown in Figure 1, the setting circuit parameters in the experiment were composed of the charging capacitance of $2 \mu \mathrm{F}$, the series resistance $\left(R_{e}\right)$ of $0.1 \Omega$, the series inductance $\left(L_{e}\right)$ of $25 \mu \mathrm{H}$, and the charging voltage $\left(V_{c h}\right)$ of $69 \mathrm{kV}$. The IEEE model [6] as illustrated in Figure 2 was utilized in a circuit simulator to calculate the impulse current and residual voltage waveforms. The circuit parameters of the model were composed of two series resistors $\left(R_{0}\right.$ and $\left.R_{1}\right)$, two series inductors $\left(L_{0}\right.$ and $\left.L_{1}\right)$, two nonlinear resistors $\left(A_{0}\right.$ and $\left.A_{1}\right)$, and a parallel capacitor $\left(C_{0}\right)$. With the help of a genetic algorithm as described in Section 4, those circuit parameters of the model were determined by matching the residual voltage from simulation with that from the experiment. As shown in Figures 3 and 4, the calculated current waveform 
agreed well with the experimental result. The calculated peak voltage deviated from the experimental one by only $2 \%$. However, the calculated residual voltage deviated from the experimental one. It was found that the calculated time to the peak of the residual was longer that the experimental one, and the spurious oscillation of the calculated residual voltage occurred in the late time or in the non-conductive state of the arrester.

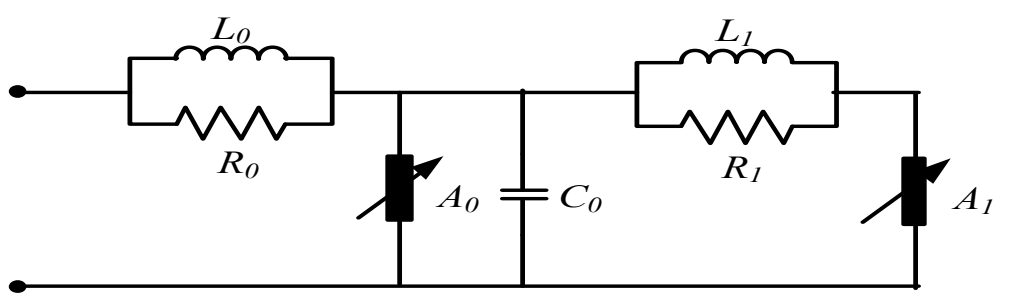

Figure 2. IEEE model of a surge arrester.

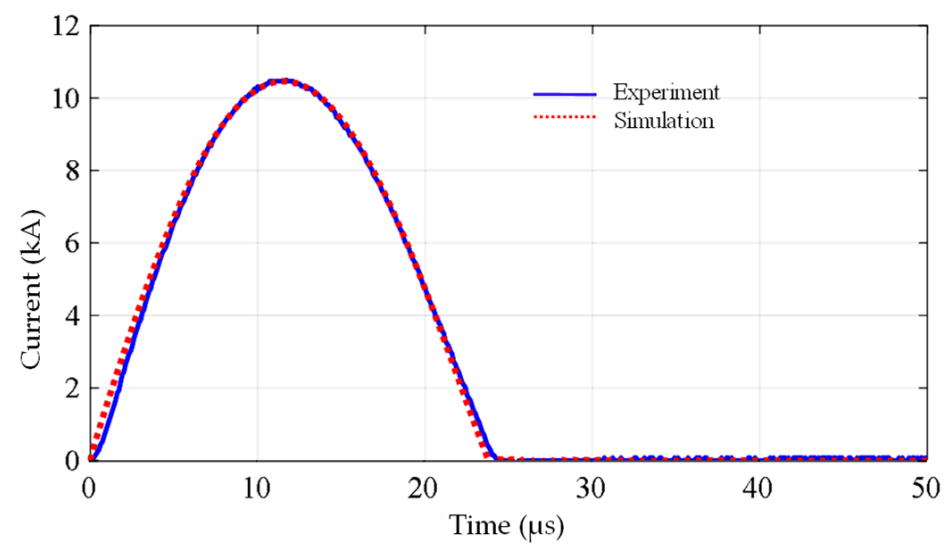

Figure 3. Comparison of the injected impulse current waveforms.

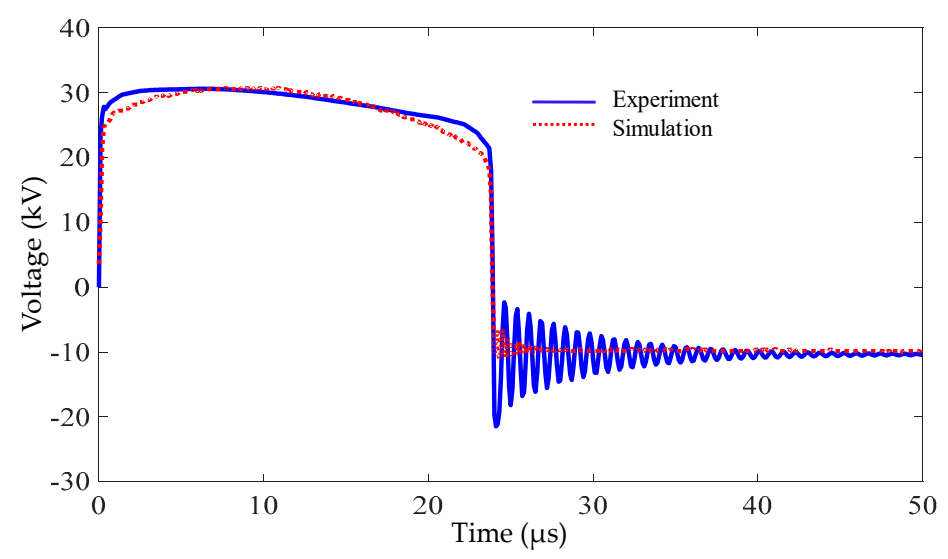

Figure 4. Comparison of the residual voltage waveforms across the arrester.

\section{Simplified and Accurate Model of a Surge Arrester}

In the results presented in Section 2, the conventional arrester model provided inaccurate results when they were compared to the experimental ones. In this section, a simplified and accurate model of a surge arrester as shown in Figure 5 is proposed to overcome the problems of the conventional model. The circuit parameters of the model were composed of the internal resistor $\left(R_{0}\right)$ in parallel with the internal inductor $\left(L_{0}\right)$, the nonlinear resistor $\left(A_{0}\right)$, and the damping resistor $\left(R_{2}\right)$ in series with the internal capacitor $\left(C_{2}\right)$. 


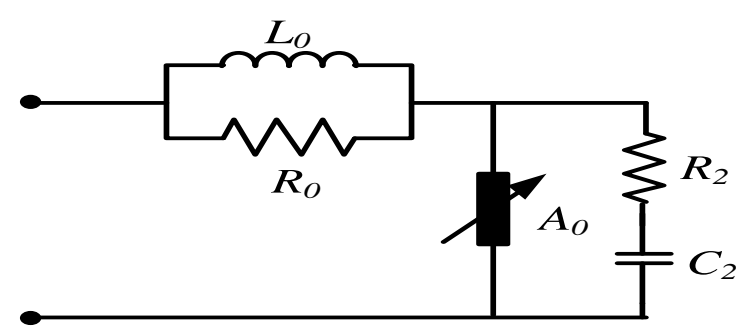

Figure 5. Simplified arrester model.

As mentioned above, the generation circuit, the parasitic impedance, i.e., series inductance $\left(L_{p}\right)$ and series resistance $\left(R_{p}\right)$, and the nonlinear characteristic of a surge arrester must be taken into account in the real impulse current generation. The simplified equivalent circuit including the parasitic impedance and the proposed arrester model is illustrated in Figure 6. In real practice, it is possible to measure the charging capacitance, the charging voltage $\left(V_{c h}\right)$, and the arrester capacitance precisely, but it is quite hard to measure other circuit parameters. However, the characteristic of the nonlinear resistor $\left(A_{0}\right)$ can be approximated from the experimental results of voltage and current across the arrester. As shown in Figure 7, in this paper, a piecewise linear curve drawn through the center of the data of voltage and current of the arrester was employed to represent the characteristic of the nonlinear resistor. A genetic algorithm was employed to search the unknown circuit parameters of the generation circuit and of the arrester model to match residual voltage $\left(v_{r}\right)$ waveforms from the experiment.

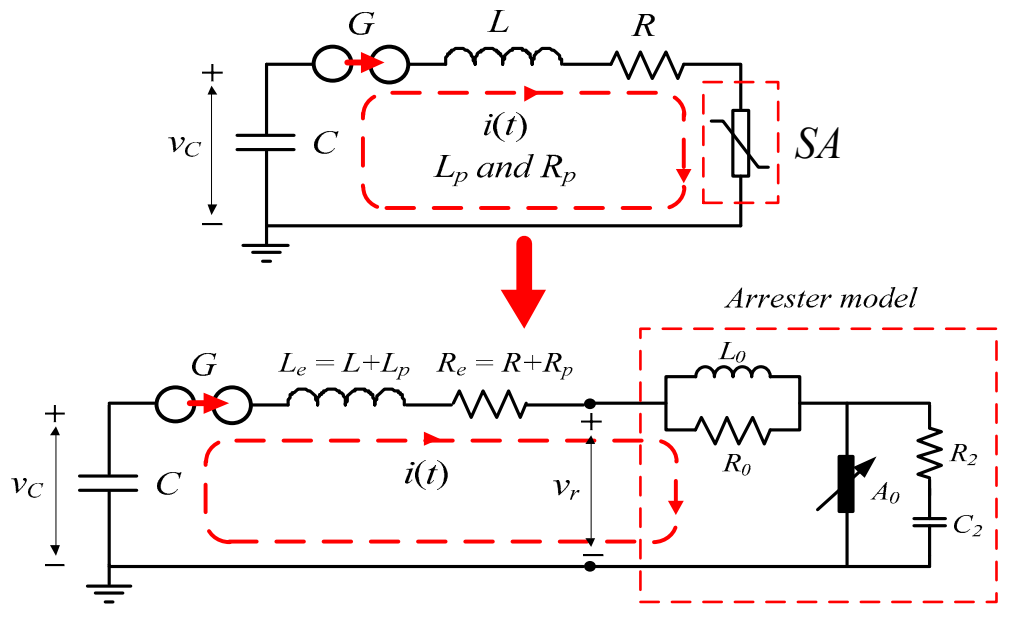

Figure 6. Equivalent circuit of the impulse current generation circuit including the parasitic impedance and the arrester model.

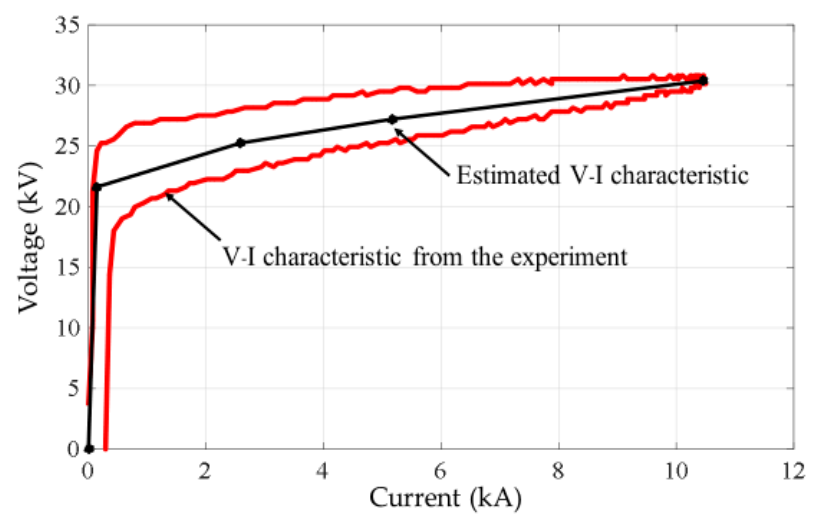

Figure 7. Approximated characteristic of the nonlinear resistor in the proposed model. 


\section{Genetic Algorithm}

A genetic algorithm (GA) is inspired by the process of natural selection. The genetic algorithm is a kind of stochastic optimization. In this paper, the genetic algorithm [16,17] was utilized to search the appropriate circuit parameters, i.e., the equivalent inductance $\left(L_{e}\right)$, the equivalent resistance $\left(R_{e}\right)$, the internal arrester inductance $\left(L_{0}\right)$, the internal arrester resistance $\left(R_{0}\right)$, the damping resistance $\left(R_{2}\right)$, and the charging voltage $\left(V_{c h}\right)$. The genetic algorithm searches the input parameters (the circuit parameter in the vector form; $X$ ) to minimize objective function $(O b(X))$, as given in Equation (1).

$$
O b(X)=\sum_{i=1}^{n}\left(v_{r(\exp )}(i)-v_{r(\operatorname{sim})}(X, i)\right)^{2}
$$

where $v_{r(\exp )}$ and $v_{r(\operatorname{sim})}$ are the residual voltages from experiment and simulation using the arrester model. $i$ is the $i$ th residual voltage point and $n$ is a number of points of the measured and simulated residual voltages.

The flow chart based on the genetic algorithm for searching the most proper circuit parameters is presented in Figure 8 .

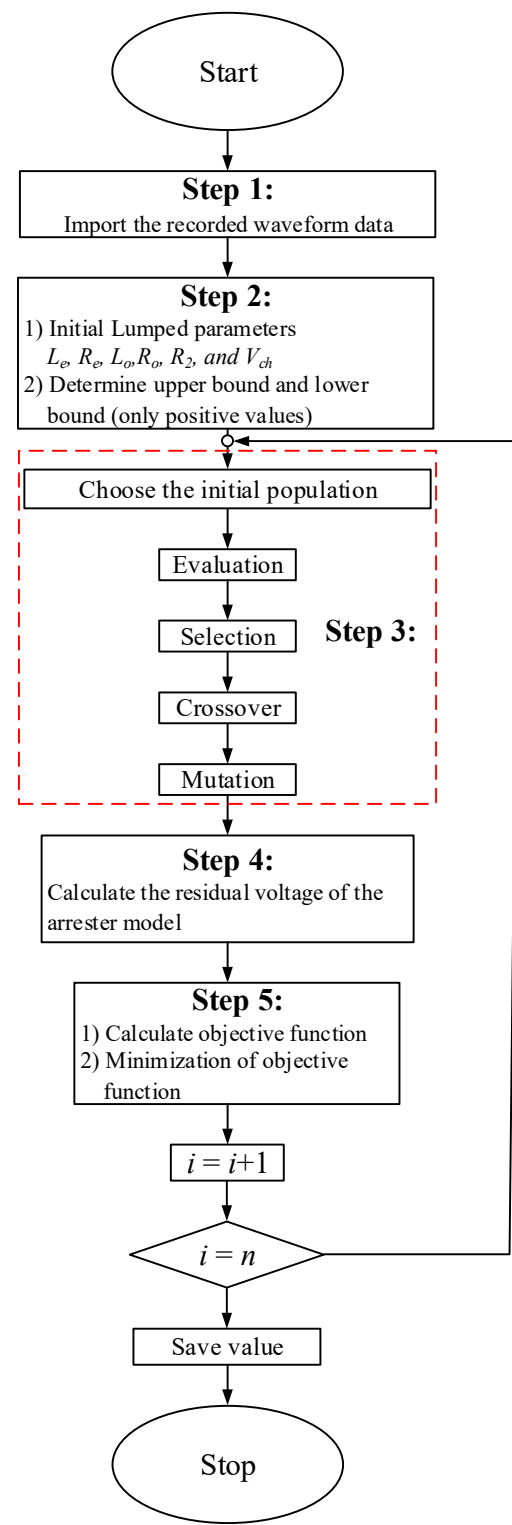

Figure 8. Flowchart of the presented genetic algorithm. 


\section{Verification of the Proposed Model}

To express the validity of the proposed model, two experiments were carried out on two arresters. The first and the second arresters had the nominal discharge currents of $10 \mathrm{kA}$ and $2.5 \mathrm{kA}$, respectively. In the first experiment, the lightning impulse current of $10 \mathrm{kA}$ was generated through the first arrester. The nonlinear characteristic of the arrester as shown in Figure 7 was used in the model construction. The genetic algorithm was utilized to search the appropriate unknown circuit parameters. As shown in Figures 9 and 10, the calculated current and residual voltage waveforms agreed well with the experimental results. The time to peak of the calculated residual voltage was almost the same time of the experimental one. The calculated peak current and voltage deviated from the experimental ones by only $0.25 \%$ and 0.2 , respectively.

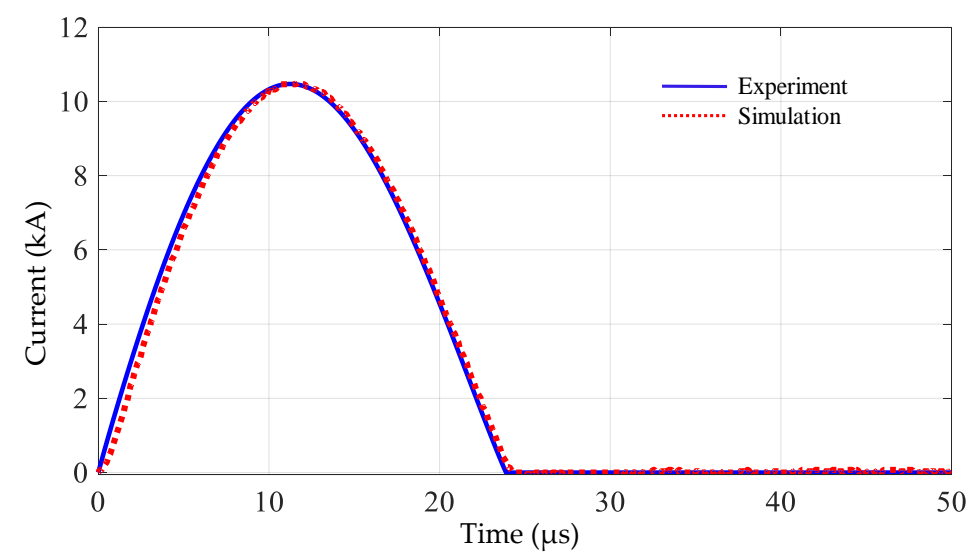

Figure 9. Comparison of the simulated and experimental lightning impulse current waveforms.

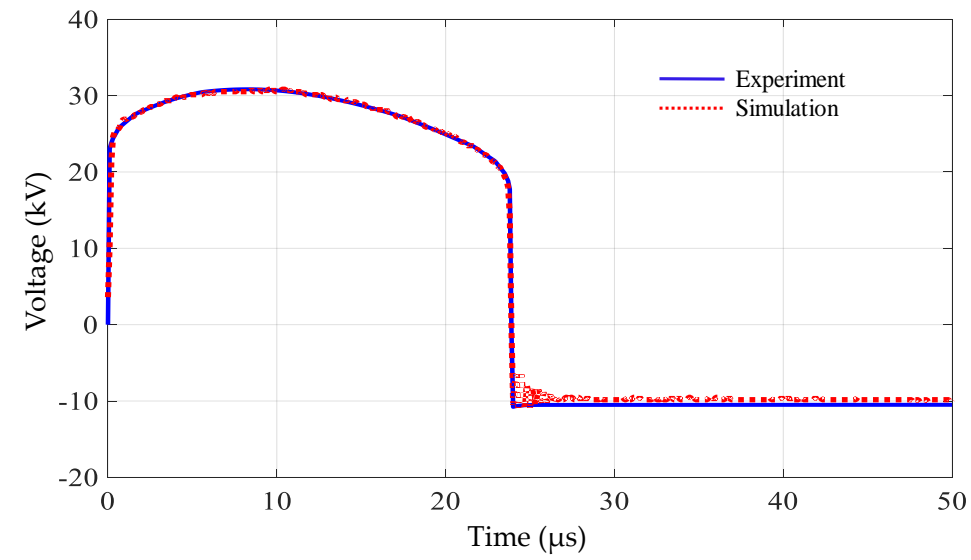

Figure 10. Comparison of the residual voltage waveforms across the arrester in a case of lightning impulse current injected.

In the second experiment, the steep impulse current of $2.5 \mathrm{kA}$ was generated through the second one. The comparisons of the generated currents and the residual voltages from the experiment and from the proposed model are shown in Figures 11 and 12. Good agreements of the generated currents and the residual voltages were found in both cases. As shown in Figures 3 and 4, the calculated current waveform agreed quite well with the experimental result. The time to peak of the calculated residual voltage was almost the same time of the experimental one. The calculated peak current deviated from the experimental one by $5 \%$. The high oscillation of the residual voltage occurred around the peak time, which is quite different from the model one. 


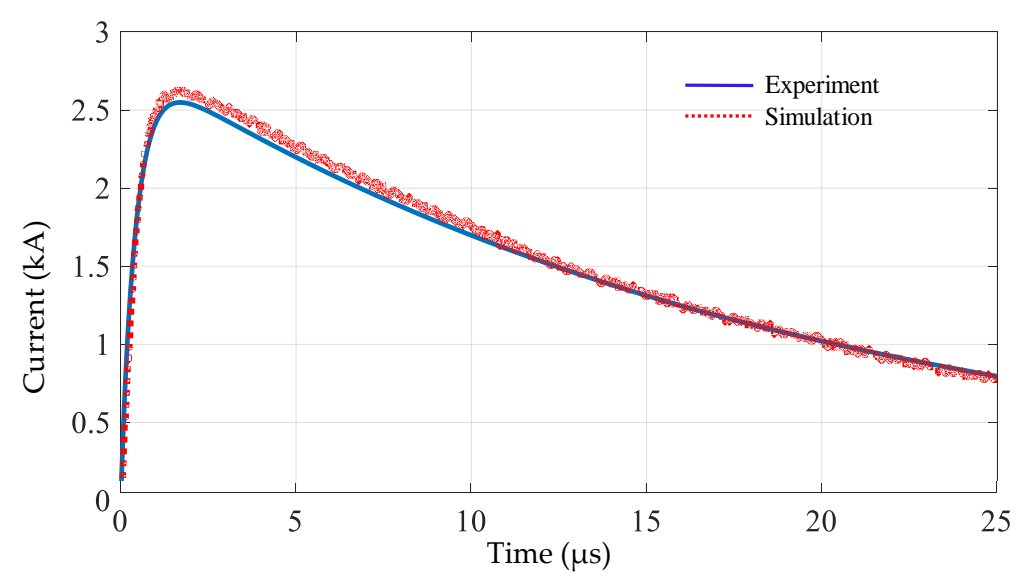

Figure 11. Comparison of the simulated and experimental steep impulse current waveforms.

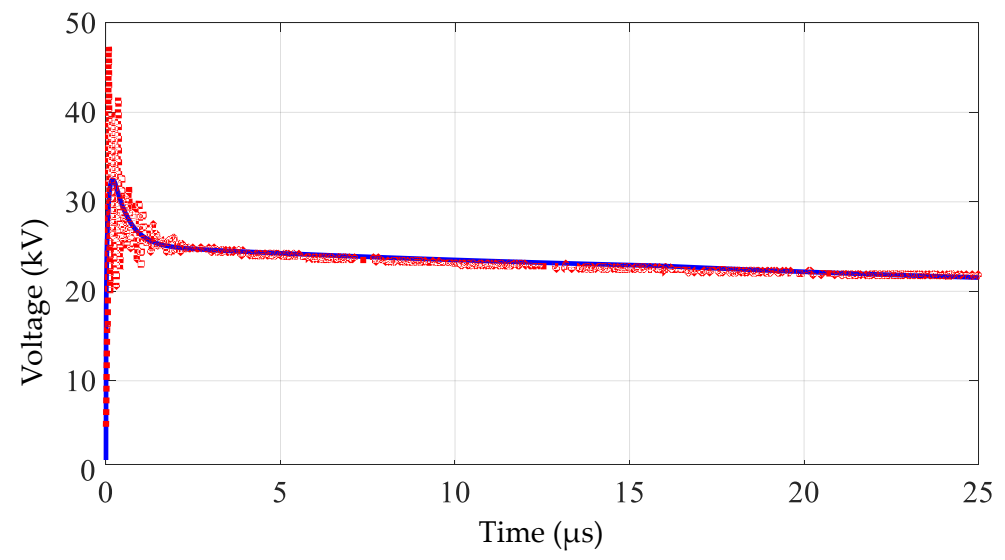

Figure 12. Comparison of the residual voltage waveforms across the arrester in a case of steep impulse current injected.

It was confirmed that the proposed model is fairly highly accurate for the residual voltage tests.

\section{Applications of the Proposed Method in the Residual Voltage Test}

It is hard for a test engineer to control the current waveform and peak without a trial and error approach. Therefore, in this section, an effective technique is proposed to determine the charging voltage for obtaining the current waveform according to the standard requirement. The technique starts from the determination of the unknown circuit parameters of the generation circuit and the proposed arrester model as shown in Figure 6. The current and residual voltage waveforms from the preliminary test with the lower current peak specified by the standard were utilized to determine the circuit parameters. Then, the previous determined model and a genetic algorithm were employed to search the charging voltage to obtain the specified current peak.

To confirm the validity of the proposed technique, some experiments on the residual voltage tests were carried out on two surge arresters with the rated voltage of $9 \mathrm{kV}$. The first arrester had the nominal discharge current of $5 \mathrm{kA}$ and the second one had the nominal discharge current of $2.5 \mathrm{kA}$.

According to the standard requirement [3] for the residual voltage test of the lightning impulse current, $0.5,1.0$, and 2.0 times the nominal discharge current are generated through the arrester and the residual voltages are examined. In the preliminary experiment, the charging capacitance and voltage were set to be $2 \mu \mathrm{F}$ and $30 \mathrm{kV}$, respectively, and the measured internal capacitance was $56 \mathrm{pF}$. From the known circuit parameters and to obtain the lightning impulse current waveform [18,19], the total inductance of 
about $30 \mu \mathrm{H}$ was required, so the series inductor $(L)$ with inductance of $30 \mu \mathrm{H}$ was connected to the generation circuit. As shown in Figure 13, the current waveform deviated from the standard requirement due to effects of the parasitic impedance and the arrester. From the experimental results of current and residual voltage waveforms as shown in Figures 13 and 14, the circuit parameters were determined by using the equivalent circuit in Figure 6. The equivalent inductance $\left(L_{e}\right)$, the equivalent resistance $\left(R_{e}\right)$, the internal arrester inductance $\left(L_{0}\right)$, the internal arrester resistance $\left(R_{0}\right)$, and the damping resistance $\left(R_{2}\right)$ were $41.2 \mu \mathrm{H}, 0.1 \Omega, 4.1 \mu \mathrm{H}$, and $3.7 \mathrm{k} \Omega$, respectively. From the determined circuit parameters, the total inductance in the circuit was $45.3 \mu \mathrm{H}\left(L_{e}+L_{0}\right)$. Therefore, the series additional inductance of $14.7 \mu \mathrm{H}$ was required to obtain the lightning impulse current waveform specified by the standard. Another experiment with an additional inductance of $15 \mu \mathrm{H}$ was carried out to confirm the validity of the proposed technique. Furthermore, using the proposed technique, the calculated charging voltage of $34 \mathrm{kV}$ associating with the current peak of $2.5 \mathrm{kA}$ was set in the experiment. It was found that as shown in Figure 13, the current waveform according to the standard specification was generated when the corrected circuit parameter was applied in the generation circuit. Moreover, the calculated residual voltage agreed well with that from the experiment as shown in Figure 14. The time to peak of the calculated residual voltage was almost the same as the experimental one. The calculated peak current and voltage deviated from the experimental ones by only $0.55 \%$ and $0.35 \%$, respectively.

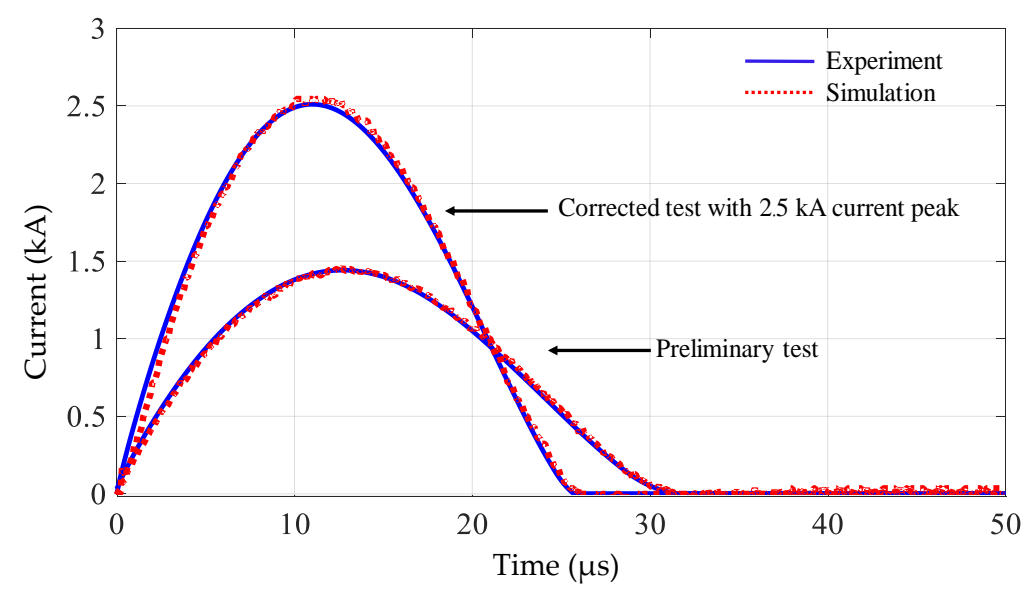

Figure 13. Comparison of the generated current waveforms in cases of the preliminary test and the corrected one.

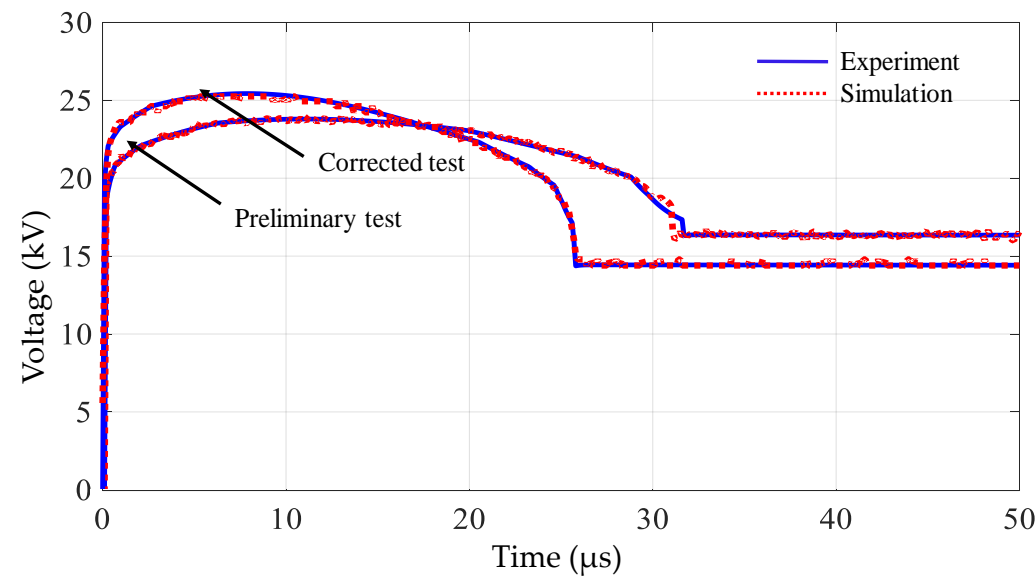

Figure 14. Comparison of the residual voltage waveforms across the arrester in cases of the preliminary test and the corrected one. 
In a similar manner, the proposed technique with the equivalent circuit associated with the current peak of $2.5 \mathrm{kA}$ was applied to search the appropriate charging voltages associated with the current peaks of $5 \mathrm{kA}$ and $10 \mathrm{kA}$. The piecewise linear curve used to estimate the nonlinear characteristic of the nonlinear resistor $\left(A_{0}\right)$ is illustrated in Figure 15. From the proposed technique, the equivalent inductance $\left(L_{e}\right)$, the equivalent resistance $\left(R_{e}\right)$, the internal arrester inductance $\left(L_{0}\right)$, the internal arrester resistance $\left(R_{0}\right)$, and the damping resistance $\left(R_{2}\right)$ were $27.1 \mu \mathrm{H}, 0.1 \Omega, 4.0 \mu \mathrm{H}$, and $3.6 \mathrm{k} \Omega$, respectively. The charging voltages to obtain the current peaks of $5 \mathrm{kA}$ and $10 \mathrm{kA}$ were $46 \mathrm{kV}$ and $69 \mathrm{kV}$, respectively. Comparisons of the experiment and simulated waveforms by the proposed technique are shown in Figures 16 and 17. Good agreement was found in the case of $5 \mathrm{kA}$ current peak but deviation occurred in the case of $10 \mathrm{kA}$ current peak. In the case of $5 \mathrm{kA}$ current application, the calculated peak current and voltage deviated from the experimental ones by only $0.73 \%$ and $0.88 \%$, respectively. In the case of $10 \mathrm{kA}$ current application, the calculated peak current and voltage deviated from the experimental ones by $4.1 \%$ and $8.1 \%$, respectively. However, in terms of current generation in the case of $10 \mathrm{kA}$ current peak, the deviation is acceptable because the current peak deviation of $4.1 \%$ was less than $10 \%$ according to the standard tolerance.

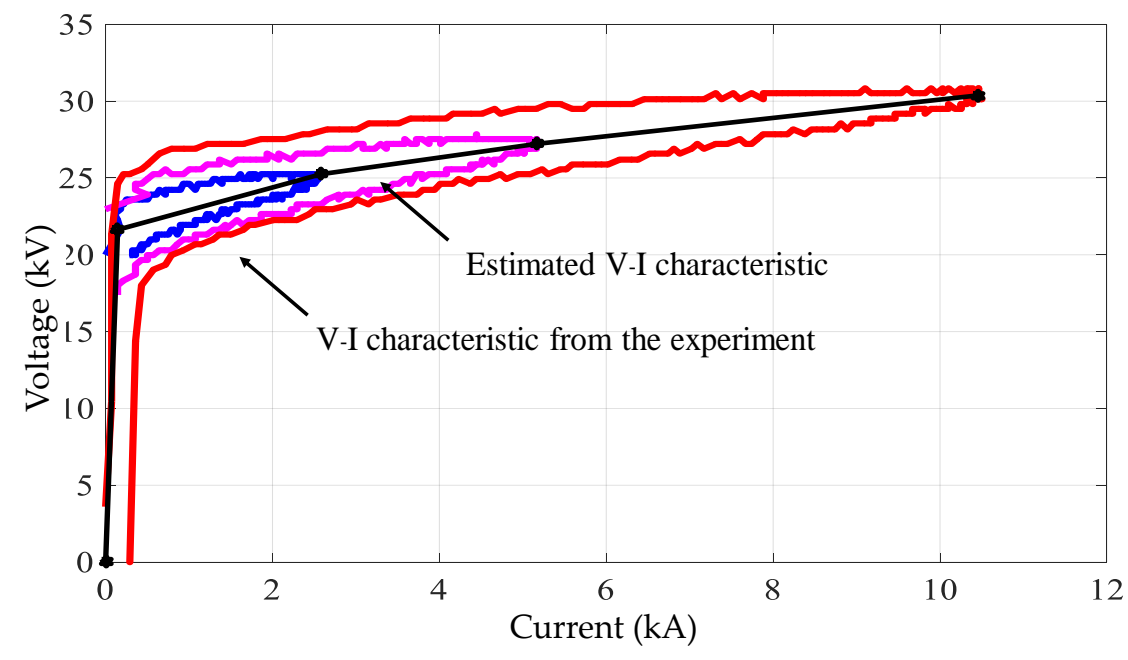

Figure 15. Voltage and current characteristic of the arrester under test and estimated piecewise linear characteristic of the nonlinear resistor.

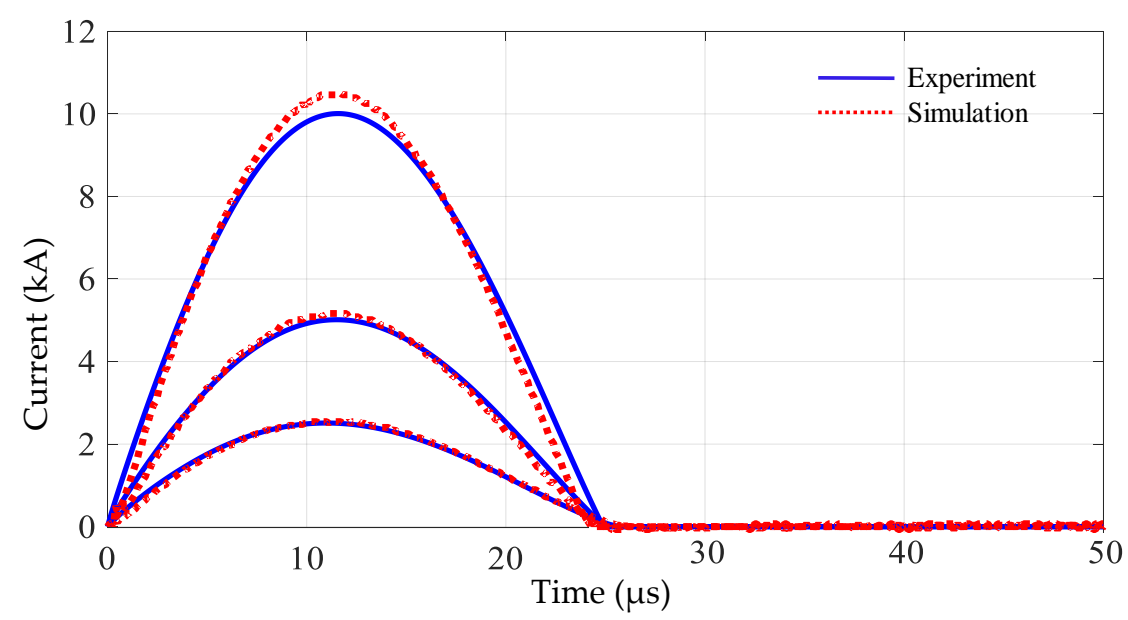

Figure 16. Comparison of the generated current waveforms from the proposed model and experiment. 


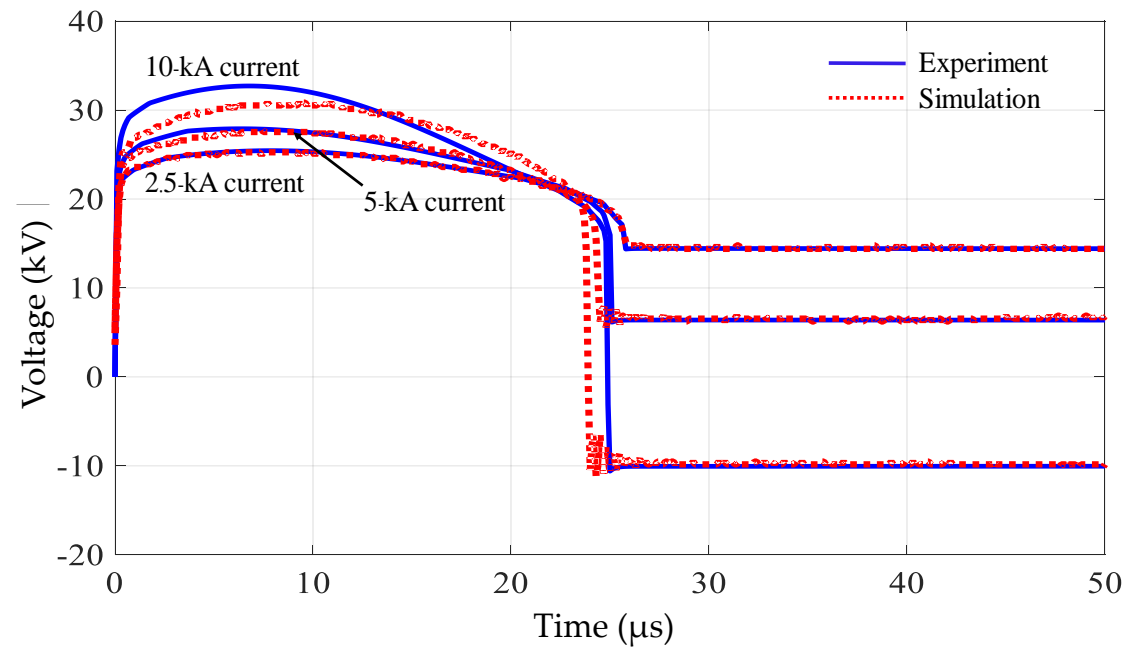

Figure 17. Comparison of the residual voltage waveforms across the arrester from the proposed model and experiment.

To obtain higher accuracy in the generation of the $10 \mathrm{kA}$ current peak, the proposed technique was applied to model the equivalent circuit using the waveforms in the case of the $5 \mathrm{kA}$ current peak and it was employed to determine the charging voltage to obtain the current peak of $10 \mathrm{kA}$. From the experimental results of current and residual voltage waveforms as shown in Figures 15 and 16, the circuit parameters were determined by using the equivalent circuit in Figure 6. The equivalent inductance $\left(L_{e}\right)$, the equivalent resistance $\left(R_{e}\right)$, the internal arrester inductance $\left(L_{0}\right)$, the internal arrester resistance $\left(R_{0}\right)$, and the damping resistance $\left(R_{2}\right)$ were $26.9 \mu \mathrm{H}, 0.1 \Omega, 2.4 \mu \mathrm{H}$, and $3.1 \mathrm{k} \Omega$, respectively. Using the model of the $5 \mathrm{kA}$ current peak, the calculated charging voltage to obtain the current peak of $10 \mathrm{kA}$ was $67.3 \mathrm{kV}$ and a charging voltage of 67.5 was set in the experiment. Comparison of the generated currents by simulation with the proposed model and that from the experiment is shown in Figure 18. In addition, the comparison of the experimental and simulated residual voltages is shown in Figure 19. A better agreement between the simulated and experimental was found. The calculated peak current and voltage deviated from the experimental ones by only $0.43 \%$ and $0.56 \%$, respectively.

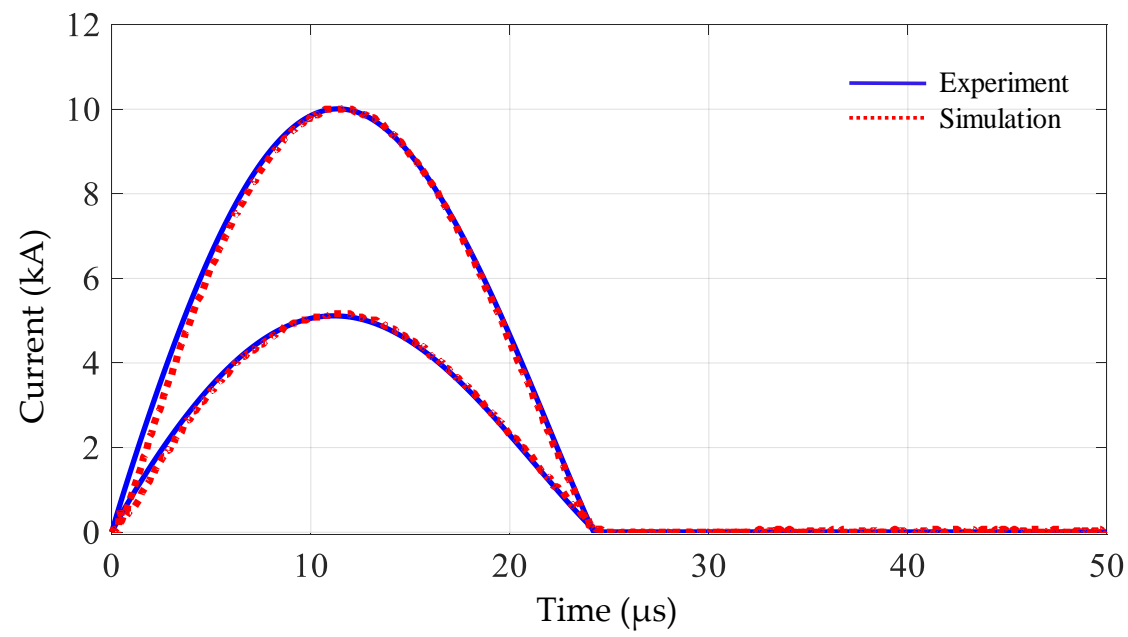

Figure 18. Comparison of the generated current waveforms from the proposed model and experiment. 


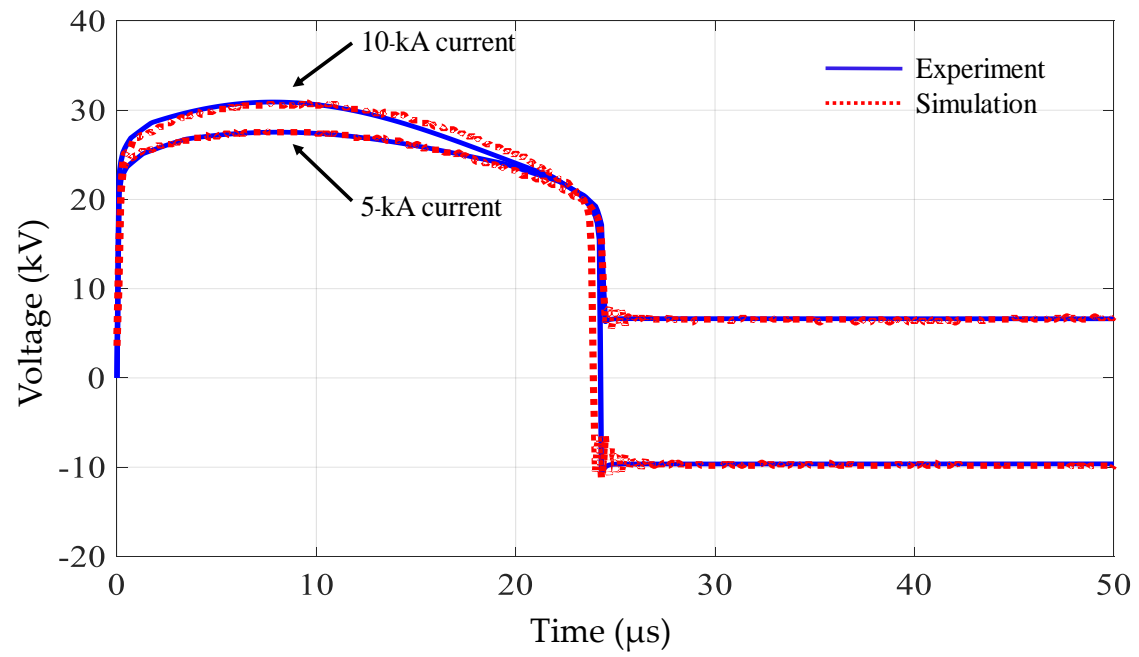

Figure 19. Comparison of the residual voltage waveforms across the arrester from the proposed model and experiment.

In a similar manner, the proposed technique was applied for the residual voltage test on the arrester with the nominal discharge current of $2.5 \mathrm{kA}$. The preliminary test with a steep impulse current was carried out at the current peak of $1.25 \mathrm{kA}$. For the steep impulse current generation, the charging capacitance, the charging voltage, and the additional resistance were set to $2 \mu \mathrm{F}, 78 \mathrm{kV}$, and $38 \Omega$, respectively, and the measured internal capacitance was $50 \mathrm{pF}$. From the calculation using the proposed technique, the equivalent inductance $\left(L_{e}\right)$, the equivalent resistance $\left(R_{e}\right)$, the internal arrester inductance $\left(L_{0}\right)$, the internal arrester resistance $\left(R_{0}\right)$, and the damping resistance $\left(R_{2}\right)$ were $14 \mu \mathrm{H}, 0.1 \Omega, 2.8 \mu \mathrm{H}$, and $198 \Omega$, respectively. Using the proposed technique to obtain the current peak of $2.5 \mathrm{kA}$, the calculated charging voltages was $134.5 \mathrm{kV}$ and the setting charging voltage in the experiment to confirm the validity of the proposed technique was $135 \mathrm{kV}$. Comparisons of the experiment and simulated waveforms by the proposed technique are shown in Figures 20-22, in which good agreement is found. It was confirmed that the proposed technique is very effective in the residual voltage tests. In the case of $2.5 \mathrm{kA}$ current application, the calculated peak current deviated from the experimental one by $7.8 \%$, which is still in the standard tolerance.

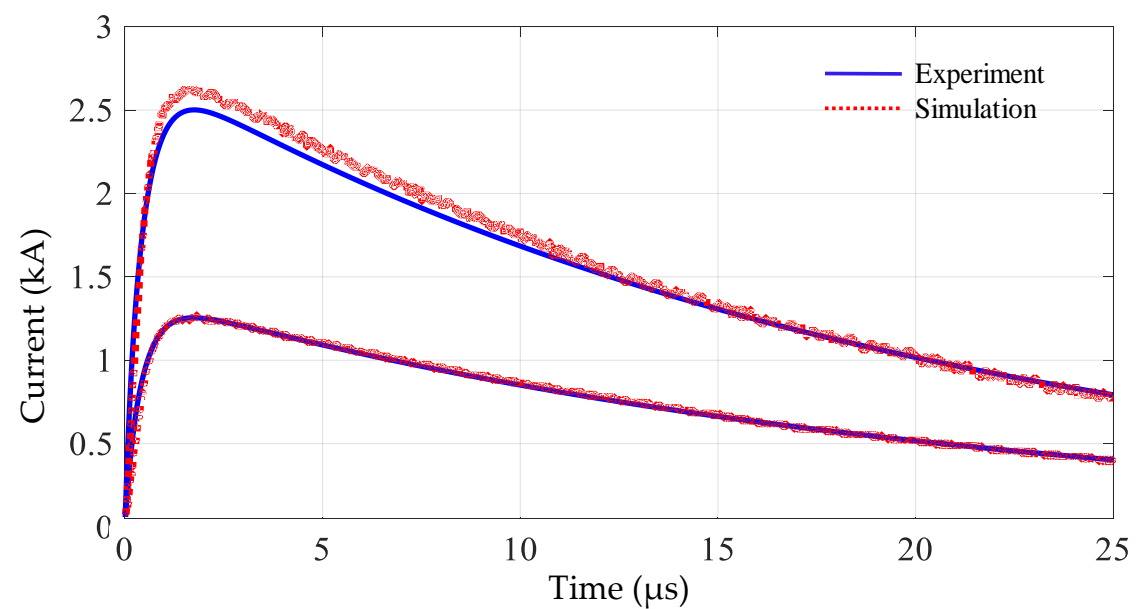

Figure 20. Comparison of the generated current waveforms from the proposed model and experiment. 


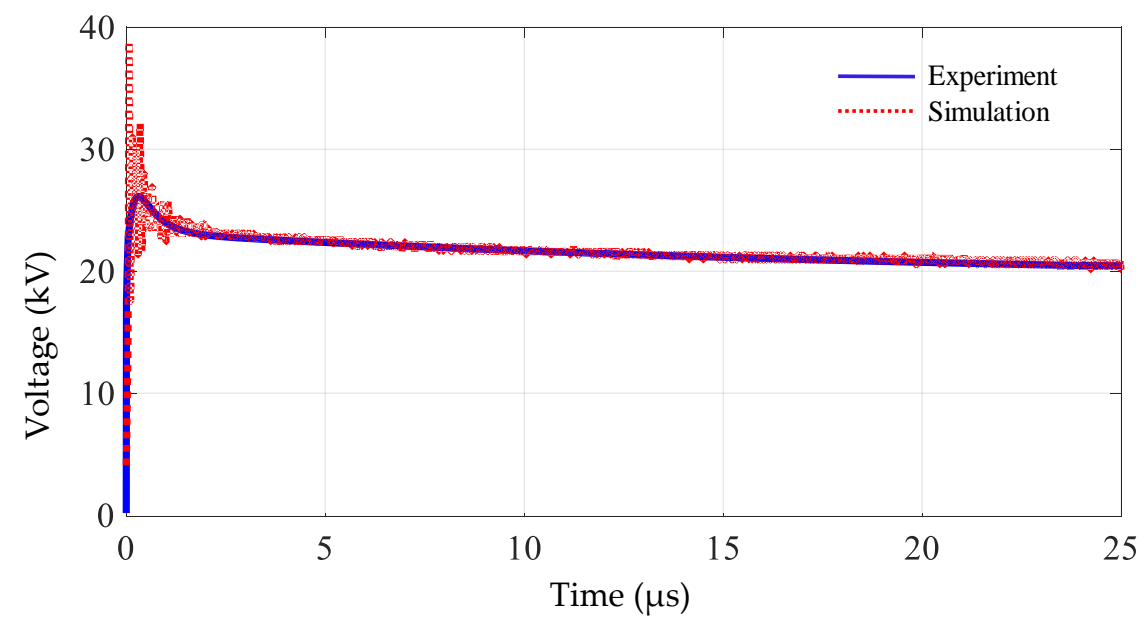

Figure 21. Comparison of the residual voltage waveforms across the arrester from the proposed model and experiment in a case of $1.25 \mathrm{kA}$ current peak.

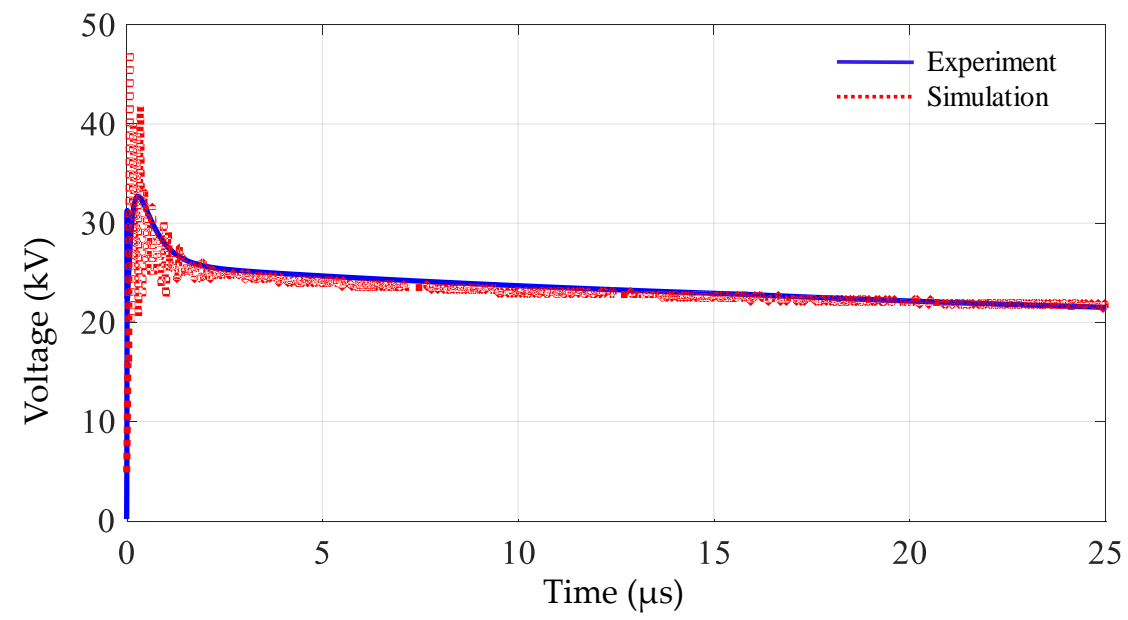

Figure 22. Comparison of the residual voltage waveforms across the arrester from the proposed model and experiment in a case of $2.5 \mathrm{kA}$ current peak.

\section{Conclusions}

A simplified and accurate model of a surge arrester for the residual voltage tests was proposed in this paper. The validation of the proposed model was verified in comparison with some experiments. Furthermore, the technique for the estimation of setting circuit parameters and the charging voltage to obtain the specified current waveform and peak was proposed. In addition, the residual voltage associated with the specified current was estimated precisely. The validity of the proposed technique was verified by the experiments. It was confirmed that the proposed technique is very useful in the residual voltage tests of arresters and helps test engineers in the selection of appropriate circuit components without a trial and error approach.

Author Contributions: Conceptualization, P.Y. and S.L.; methodology, S.L. and P.Y.; validation, S.L.; formal analysis, N.T.; investigation, P.Y. and S.L.; writing—original draft preparation, P.Y. and S.L.; writing-review and editing, P.Y. and S.L.; supervision, P.Y. All authors have read and agreed to the published version of the manuscript.

Funding: This project is funded by National Research Council of Thailand.

Acknowledgments: The authors would like to give special acknowledgement to the School of Engineering, King Mongkut's Institute of Technology Ladkrabang for providing the facility in this research work. In addition, this project is funded by National Research Council of Thailand. 
Conflicts of Interest: The authors declare no conflict of interest.

\section{References}

1. Eddie, S.; Innocent, E.D.; Sindisiwe, C.M. Lightning Performance and Economic Analysis of an Overhead 88 kV Power Delivery Network with Enhanced Protective Systems. Energies 2020, 13, 6519.

2. IEC 61641-1. Low-Voltage Surge Protective Devices_Part 1; IEC: Geneva, Switzerland, 2014.

3. IEC 60099-4. Surge Arresters. Part 4: Metal-Oxide Surge Arresters without Gaps for A.C. System; IEC: Geneva, Switzerland, 2014.

4. IEEE Standard 4TM-2013. IEEE Standard for High-Voltage Testing Techniques; IEEE SA: Piscataway, NJ, USA, 2013.

5. IEC 62475. High-Current Test Techniques: Definitions and Requirements for Test Currents and Measuring Systems; IEC: Geneva, Switzerland, 2010.

6. IEEE.W.3.4.11. Of Surge Protection Pevices Committee. Modeling of metal oxide surge arresters. IEEE Trans. Power Deliv. 1992, 7, 301-309.

7. Montano, R.; Edirisinghe, M.; Cooray, V.; Roman, F. Behavior of low-voltage surge protective devices under high-current derivative impulses. IEEE Trans. Power Deliv. 2007, 22, 2185-2190. [CrossRef]

8. Zeinoddini-Meymand, H.; Vahidi, B.; Naghizadeh, R.A.; Moghimi-Haji, M. Optimal surge arrester parameter estimation using a PSO-based multiobjective approach. IEEE Trans. Power Deliv. 2013, 28, 1758-1769. [CrossRef]

9. Tuczek, M.N.; Hinrichsen, V. Recent experimental findings on the single and multi-impulse energy handling capability of metal-oxide varistors for use in high-voltage surge arresters. IEEE Trans. Power Deliv. 2014, 29, 2197-2205. [CrossRef]

10. Sato, S.; Okamoto, Y.; Nishimura, S. Impulse current waveform parameters determination with ZnO load. In Proceedings of the 2010 IPEC Conference, Sapporo, Japan, 21-24 June 2010; pp. 78-82.

11. Sabiha, N.A.; Mahmood, F.; Abd-Elhady, A.M. Failure risk assessment of surge arrester using paralleled spark gap. IEEE Access 2020, 8, 217098-217107. [CrossRef]

12. Yvonne, S.L.; Erion, G.; Herbert, D.G. Electrothermal optimization of field grading systems of station class surge arresters. IEEE J. Multiscale Multiphys. Comput. Tech. 2019, 4, 29-35.

13. Reza, S.; Javad, G.; Keyhan, S. Estimation of energy stress of surge arresters considering the high-frequency behavior of grounding systems. IEEE Trans. Electromagn. Compat. 2018, 6, 917-925.

14. Sato, S.; Nishimura, S.; Seki, S. Parameters determination of oscillatory impulse current waveform. IEEJ Trans. Fundam. Mater. 2010, 130, 265-271. [CrossRef]

15. Lu, J.; Xie, P.; Fang, Z.; Hu, J. Electro-thermal modeling of metal-oxide arrester under power frequency applied voltages. Energies 2018, 11, 1610. [CrossRef]

16. Yang, X. Engineering Optimization: An Introduction with Metahueristic Applications; John Wiley \& Sons: Hoboken, NJ, USA, 2010; pp. 173-176.

17. Mehdi, B.; Davood, A.; Hassan, B.; Ebrahim, R. Identification of transient model parameters of transformer using genetic algorithm. In Proceedings of the International Conference on Power System Technology, Hangzhou, China, 24-28 October 2010; pp. 1-6.

18. Yutthagowith, P. Effective technique for circuit and waveform parameter extraction in impulse current tests and its application. IEEE Trans. Power Deliv. 2015, 31, 704-710. [CrossRef]

19. Yutthagowith, P.; Triruttanapiruk, N. A program for design of passive circuits of impulse current generation. In Proceedings of the ISET, Chiang Mai, Thailand, 24-26 April 2013; pp. 1-4. 